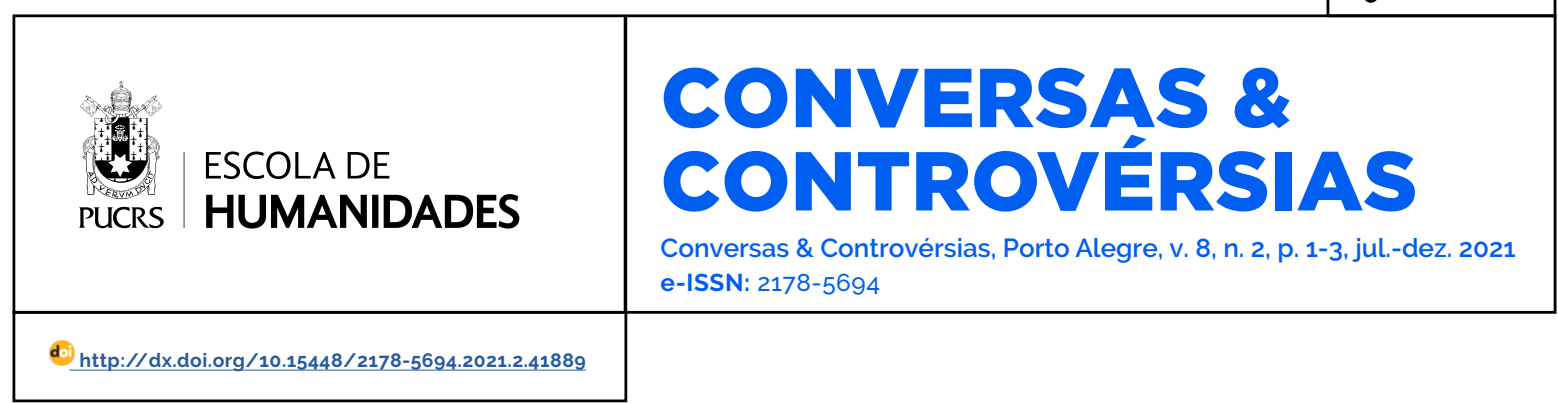

SEÇÃO: APRESENTAÇÃO

\title{
Crise sistêmica internacional e regimes democráticos
}

International systemic crisis and democratic regimes

\section{Felipe Rocha de Carvalho ${ }^{1}$ \\ orcid.org/0000-0002-0679-6092 feliperochacarvalho@gmail.com}

\section{Isabella Cruzichi'}

orcid.org/0000-0002-9594-1115 isabellacruzichi@gmail.com

\section{Kamilla Raquel Rizzi ${ }^{3}$ \\ https://orcid.org/0000-0002 8462-7497 \\ kamillarizzi@unipampa.edu.br}

Recebido em: 22/03/2021 Aprovado em: 31/05/2021 Publicado em: 01/12/2021.

\section{(c) (i)}

Artigo está licenciado sob forma de uma licença Creative Commons Atribuição 4.0 Internacional.
Historicamente, a América Latina presenciou diversos períodos de autoritarismo ao longo da história. A construção da cultura política de participação se deu em meio a períodos autoritários e períodos democráticos, no entanto, sem muito incentivo ou preparação para o exercício da cidadania. Mesmo em períodos autoritários, nos quais a participação dos cidadãos no meio político não era incentivada e, até mesmo, suprimida, como no caso de regimes ditatoriais, houve manifestações, protestos, movimentos que lutavam por direitos, por liberdades e, até mesmo, pela democracia e o direito de participar, como no caso das "Diretas Já" no Brasil, entre 1983 e 1984, que reivindicava eleições diretas para presidente em meio a um regime militar, ou o caso mais recente da Venezuela, no qual ainda ocorrem protestos e manifestações em defesa da democracia, que muitos afirmam estar em risco ou até mesmo desaparecida a partir dos governos de Hugo Chávez e Nicolás Maduro.

A característica mais marcante do atual sistema mundial é de crise e transição em todos os âmbitos. Instabilidades securitárias e politicas, crises econômicas, aprofundamento das desigualdades sociais, locais e regionais, fome, desemprego, desregulamentação trabalhista, questões ambientais não valorizadas, organismos multilaterais questionados, dependência da periferia em relação aos centros desenvolvidos em Ciência \& Tecnologia, aumento dos desajustes na política internacional. Uma gama de nuances que se agudizaram ainda mais a partir de março de 2020, quando a Organização Mundial de Saúde decretou a pandemia de COVID-19.

Logo, é com satisfação que apresentamos o Dossiê "Crise Sistêmica Internacional e Regimes Democráticos" da revista Conversas \& Controvérsias, o qual traz contribuições importantes para a compreensão do sistema mundial contemporâneo, em transformação profunda nas últimas três décadas. Apesar de mais de um ano e meio de pandemia da COVID-19 - com todos os desafios sociais, políticos, econômicos e institucionais aí decorrentes -, o Dossiê captou publicações acadêmicas de qualidade, as quais analisam, especificamente, objetos de estudo oriundos da periferia 
do sistema mundial contemporâneo, em plena fase de tensões, mudanças e inconstâncias.

Em "Os desafios para a consolidação da democracia na Ásia Central pós-soviética: o caso do Uzbequistão sob a administração de Islam Karimov", Guilherme Geremias da Conceição analisa o processo pós-soviético de democratização da República do Uzbequistão. Contrapondo uma literatura tradicional que concebe a democracia como um conceito universalmente aplicável e objetivo, o texto sustenta a tese de que o Uzbequistão visa, por uma via constitucional, a testar novos modelos democráticos. Valendo-se de indicadores sobre o governo Karimov e considerando a complexa inter-relação de fatores externos, o autor traça as particularidades e os desafios para a consolidação do regime democrático uzbeque.

Ainda sobre a construção de democracias em Estados periféricos do sistema mundial, Maurício Dias, Nicole Fava e Bruno Teixeira, no trabalho intitulado "Nicarágua em Crise: Governo de Daniel Ortega (2007-2021) e o Desmantelamento Democrático", buscam compreender, por meio da análise dos processos históricos e revolucionários, o estabelecimento do sistema democrático na Nicarágua durante os séculos XIX e XX, destacando como Ortega logrou a instauração de um regime político hibrido no país. Ao recobrar as fragilidades da democracia nicaraguense, perceptiveis desde sua gênese em 1984, os autores contribuem com importantes reflexões sobre as raízes da gradual degeneração das estruturas democráticas nacionais verificada nos últimos anos.

Discutindo a construção democrática no continente africano, o artigo "A rememoração do Genocídio de Ruanda e seus efeitos no presente democrático: uma análise a partir da necropolítica midiática", de autoria de Júlia dos Santos Acerbi, Lays Serpa de Souza de Oliveira e Silva e Tiago Grossi Dornelas, debruça-se sobre o estudo da influência das narrativas disseminadas durante o genocidio de Ruanda para o presente democrático do país. Utilizando-se da teorização sobre necropolítica de Achile Mbembe, os autores traçam uma análise da atuação da mídia como articuladora de narrativas que impeliam a polarização durante o genocídio. Em paralelo, os autores discorrem sobre os efeitos desse processo na inviabilização do progresso democrático no país.

No artigo intitulado "Cultura política e apoio à democracia: comparações entre Brasil e Venezuela", Domingos Sávio Campos de Azevedo e Fernanda Weirich realizam uma comparação entre os dois países por meio de dados do Latinobarómetro de 2018, com o objetivo de averiguar o apoio das populações em questão à democracia. Por possuírem uma percepção de suas respectivas economias como negativas e terem IDHs semelhantes, a escolha dos casos se mostrou relevante para os autores. Ao longo do texto, são trazidas reflexões para o debate de um tema de tamanha importância na conjuntura latino-americana atual.

Em "Adesão às normas democráticas como forma de minimizar os efeitos da intolerância política", Victor Gabriel Menezes Menegassi e Naiara Sandi de Almeida Alcantara operacionalizam conceitos trazidos por Pippa Norris e Ronald Inglehart no que diz respeito à ideia de um backlash cultural como um dos propulsores da ascensão de políticos conservadores. Nesse sentido, os autores buscam verificar a existência dessa relação no Brasil, utilizando, para tanto, uma análise quantitativa do material disponibilizado pelo Latin American Public Opinion Project (LAPOP). O artigo propicia uma discussão profunda acerca da relação entre as mudanças culturais ocorridas nos últimos anos e o aumento da intolerância política.

Isabela Monti, em seu artigo "A comunidade dos iguais e o líder do verdadeiro povo: uma breve caracterização do fenômeno do populismo contemporâneo", analisa o fenômeno do populismo contemporâneo ao instrumentalizar dois conceitos: a noção de povo e a ideia de líder político. Antes de chegar no cerne de seu trabalho, a autora realiza uma discussão acerca das transformações históricas e sociais ocorridas no decorrer da segunda metade do século XX. Finalmente, são elencadas algumas conclusões sobre o populismo e sua relação com a verticalização da política.

"Os últimos vestígios de Pinochet: a consolidação da democracia chilena frente ao autoritarismo constitucional", trabalho escrito a oito mãos por 
Felipe Rocha de Carvalho - Kamilla Raquel Rizzi

Yasmim Ribas, Anna Coelho, Gabriela Dias Tironi e Clarice Söhngen, é dedicado à compreensão dos acontecimentos que se desenrolaram no ano de 2020 no Chile, após a aprovação de uma reforma constitucional. As autoras partem da conceituação de autoritarismo trazida por Norberto Bobbio para analisar tanto a ditadura chilena quanto os impactos deste período manifestos na Constituição até o presente.

Assim, é importante notar que essas análises aqui apresentadas têm em comum a percepção das instabilidades institucionais, de seus regimes de governo, de conflitos étnicos e de um espectro variado de temas, que auxiliam a compreender as rupturas e as permanências no processo histórico, as faces e as contradições, além de tendências que caracterizam nosso tempo.

Boa leitura a todos!

\section{Felipe Rocha de Carvalho}

Mestre em Ciências Sociais pela Pontifícia Universidade Católica do Rio Grande do Sul (PUCRS), em Porto Alegre, RS, Brasil; doutorando em Ciências Sociais pela Pontifícia Universidade Católica do Rio Grande do Sul (PUCRS), em Porto Alegre, RS, Brasil.

\section{Isabella Cruzichi}

Mestre em Ciência Politica pela Universidade Federal do Rio Grande do Sul (UFRGS), em Porto Alegre, RS, Brasil; doutoranda em Ciência Política pela Universidade Federal do Rio Grande do Sul (UFRGS), em Porto Alegre, RS, Brasil. Pesquisadora Assistente do Centro Brasileiro de Estudos Africanos (CEBRAFRICA), Porto Alegre, RS, Brasil.

\section{Kamilla Raquel Rizzi}

Doutora em Ciência Política pela Universidade Federal do Rio Grande do Sul (UFRGS), em Porto Alegre, RS, Brasil; mestre em Relações Internacionais pela Universidade Federal do Rio Grande do Sul (UFRGS), em Porto Alegre, RS, Brasil; professora Adjunta de Relações Internacionais na Universidade Federal do Pampa, Campus Santana do Livramento (UNIPAMPA), Santana do Livramento, RS, Brasil

Os textos deste artigo foram revisados pela Poá Comunicação e submetidos para validação dos autores antes da publicação. 